\title{
Characterization of ash particles with a microheater and gas-sensitive SiC field-effect transistors
}

\author{
C. Bur ${ }^{1,2}$, M. Bastuck ${ }^{1}$, A. Schütze ${ }^{1}$, J. Juuti ${ }^{3}$, A. Lloyd Spetz ${ }^{2,3}$, and M. Andersson ${ }^{2,3}$ \\ ${ }^{1}$ Lab for Measurement Technology, Saarland University, Saarbrücken, Germany \\ ${ }^{2}$ Div. of Applied Sensor Science, Linköping University, Linköping, Sweden \\ ${ }^{3}$ Microelectronics and Material Physics Laboratories, University of Oulu, Oulu, Finland \\ Correspondence to: C. Bur (c.bur@lmt.uni-saarland.de, chrbu@ifm.liu.se)
}

Received: 30 July 2014 - Revised: 7 October 2014 - Accepted: 1 November 2014 - Published: 24 November 2014

\begin{abstract}
Particle emission from traffic, power plants or, increasingly, stoves and fireplaces poses a serious risk for human health. The harmfulness of the particles depends not only on their size and shape but also on adsorbates. Particle detectors for size and concentration are available on the market; however, determining content and adsorbents is still a challenge.

In this work, a measurement setup for the characterization of dust and ash particle content with regard to their adsorbates is presented. For the proof of concept, ammonia-contaminated fly ash samples from a coal-fired power plant equipped with a selective non-catalytic reduction (SNCR) system were used. The fly ash sample was placed on top of a heater substrate situated in a test chamber and heated up to several hundred degrees. A silicon carbide field-effect transistor (SiC-FET) gas sensor was used to detect desorbing species by transporting the headspace above the heater to the gas sensor with a small gas flow. Accumulation of desorbing species in the heater chamber followed by transfer to the gas sensor is also possible.

A mass spectrometer was placed downstream of the sensor as a reference. A clear correlation between the SiC-FET response and the ammonia spectra of the mass spectrometer was observed. In addition, different levels of contamination can be distinguished. Thus, with the presented setup, chemical characterization of particles, especially of adsorbates which contribute significantly to the harmfulness of the particles, is possible.
\end{abstract}

\section{Introduction}

Particle emission from traffic or huge power plants poses a serious risk for human health. The harmfulness of the particles depends mainly on their size, shape and content (Buzea et al., 2007). In recent years, the amount of nano-sized particles has increased considerably, which increases the risk for human beings. (Buzea et al., 2007; NIOSH, 2013).

Particle detectors for size and concentration are available on the market and are usually based on optical systems, e.g., light scattering $(\mathrm{Xu}, 2014)$ or charging of particles (Ntziachristos et al., 2011; Lanki et al., 2011; Amanatidis et al., 2013). Surface acoustic wave resonators (SAWR) have been used to detect submicron-sized particles with a mass below $1 \mathrm{ng}$ (Thomas et al., 2013). For soot detection, sensor systems based on thermophoresis (Bjorklund, 2010) and electri- cal impedance spectroscopy (EIS) of interdigital electrodes (IDE) (Messerer, 2003; Bartscherer and Moos, 2013) are also presented. Impedance spectroscopy is also being developed to reveal particle size (Osite et al., 2011; Lloyd Spetz et al., 2013). Geiling et al. (2013) presented a hybrid particle detector based on low-temperature cofired ceramics (LTCC) which measures the interaction of single particles with an electrical field. Not only the particle itself but also its composition can be harmful, and, in particular, adsorbed substances raise the potential risk significantly. Particularly in heavy industry work place environments, workers are exposed to high concentrations of ash and dust particles, which can affect their health (Lanki et al., 2011). Identification and quantification of such particles or adsorbates may potentially be used as a method for assessment of their health effects. However, determining the content of particles is still a challenge. 
Gas-sensitive field-effect transistors based on silicon carbide as a substrate material (SiC-FET) are suitable sensors to operate in harsh environments. Development of different applications ranging from exhaust monitoring related to vehicles (Larsson et al., 2002) and small- and medium-scale power plants (Andersson et al., 2007), to ammonia detection in selective catalytic reduction (SCR) systems (Andersson et al., 2013), to sulfur dioxide detection in huge power plants (Darmastuti et al., 2014) have been demonstrated in the last years. The outstanding performance of the sensors in withstanding these environments is largely due to the chemical inertness of silicon carbide ( $\mathrm{SiC}$ ). In addition, $\mathrm{SiC}$ has a wide band gap (3.2 eV for $4 \mathrm{H}-\mathrm{SiC})$, which allows for operating temperatures up to $1000^{\circ} \mathrm{C}$ without loss of its semiconducting behavior (Lloyd Spetz et al., 1997, 2003). The $\mathrm{SiC}$ field-effect transistor can be made gas sensitive by using a catalytic gate material, like palladium (Pd), platinum (Pt) or iridium (Ir) (Lundström et al., 2007). The sensing properties of SiC-FETs depend mainly on the gate material, its structure (porosity and number of three phase boundaries), the underlying oxide and the operating temperature. Gas molecules arriving at the catalytic surface of the gate can directly adsorb, dissociate and/or react with, for example, adsorbed oxygen. Adsorbed species on the surface of the sensor change the gate to a substrate electric field, which in turn influences the concentration of mobile carriers in the channel of the transistor. This causes a shift in the IV curve of the sensor. A detailed description of the sensing mechanism can be found elsewhere (Andersson et al., 2013).

Performance of SiC-FETs in terms of sensitivity and selectivity can be enhanced by dynamic operation. It has been reported that discrimination of typical exhaust gases (Bur et al., 2012a) as well as quantification of nitrogen oxides $\left(\mathrm{NO}_{\mathrm{x}}\right)$ (Bur et al., 2012b) is possible when using temperature-cycled operation (TCO). Additionally, gate-bias-cycled operation (GBCO) together with TCO can boost the selectivity of the sensors further (Bur et al., 2014).

In this work, a new method is proposed to study the content of particles, i.e., substances adsorbed on the particles. For that, a large-scale laboratory measurement setup based on a ceramic hotplate and a SiC-FET gas sensor is suggested in order to measure the content of particles. The results presented in this paper can be seen as a proof of concept and are part of the ongoing development of a portable particle detector (Lloyd Spetz et al., 2013).

\section{Methodology}

Measuring the content of particles with a cost-effective, handheld device is a challenging task. Since not only the content of the particle itself can be harmful to humans but also adsorbed substances, we propose a setup in which either the particles themselves or their adsorbates are transformed into the gas phase in order to be detected by a gas sensor. There-

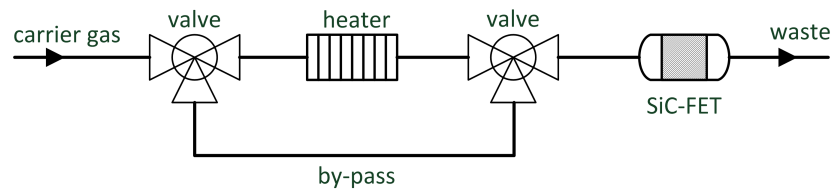

Figure 1. Schematic of the measurement setup.

fore, we suggest placing/collecting the test samples/particles on top of a ceramic heater in order to rapidly heat up the particles. The outgassing substances are then detected by a gas-sensitive field-effect transistor located downstream of the heater. In order to investigate this concept, the measurement setup shown in Fig. 1 is suggested.

The setup consists of a heater chamber, two valves, a bypass to the heater and the sensor chamber. The bypass approach gives rise to several advantages: (1) the gas sensor is always under controlled conditions, and thus no disturbances affect the sensor response, e.g., when placing the particles on top of the heater; (2) using the valves allows well defined exposure of the desorbates to the gas sensor. (3) Asynchronous operation of the valves and heater allows for example accumulation of desorbates before exposing them to the gas sensor.

However, when switching the valves we observed that the sensor response can be affected, which might be due to a change in pressure and/or flow inside the tubing system. Therefore, for preliminary measurements (Sects. 4.1-4.4), we used a simpler setup without the bypass where the sensor is connected directly to the heater chamber. Nevertheless, our suggested bypass approach is in particular interesting for an integrated particle sensor which has to accumulate particles independently on the heater. First results when using the complete setup (cf. Fig. 1) are presented in Sect. 4.5 and can be seen as an extension of the paper.

\section{Experimental}

\subsection{Gas-sensitive field-effect transistor}

For all measurements $n$-channel metal insulator semiconductor field-effect transistors (MISFET) based on silicon carbide (SiC-FET) were used (Fig. 2a). The devices are processed from 4 in. $4 \mathrm{H}-\mathrm{SiC}$ wafers with mass production technology (SenSiC AB, Kista, Sweden, and ACREO AB, Kista, Sweden). Each sensor chip holds four sensors. As catalytic gate metallizations, $25 \mathrm{~nm}$ thick porous platinum and $30 \mathrm{~nm}$ thick porous iridium films were used. The gate dimension was $300 \mu \mathrm{m}$ wide by $10 \mu \mathrm{m}$ long. A detailed description can be found elsewhere (Andersson et al., 2013). The SiC chip was glued onto a ceramic heater (Heraeus PT-6.8 M 1020, Heraeus Sensor Technology, Kleinostheim, Germany) to allow for precise heating of the sensor. As a reference, a Pt-100 temperature sensor (Heraeus GmbH, Germany) was 

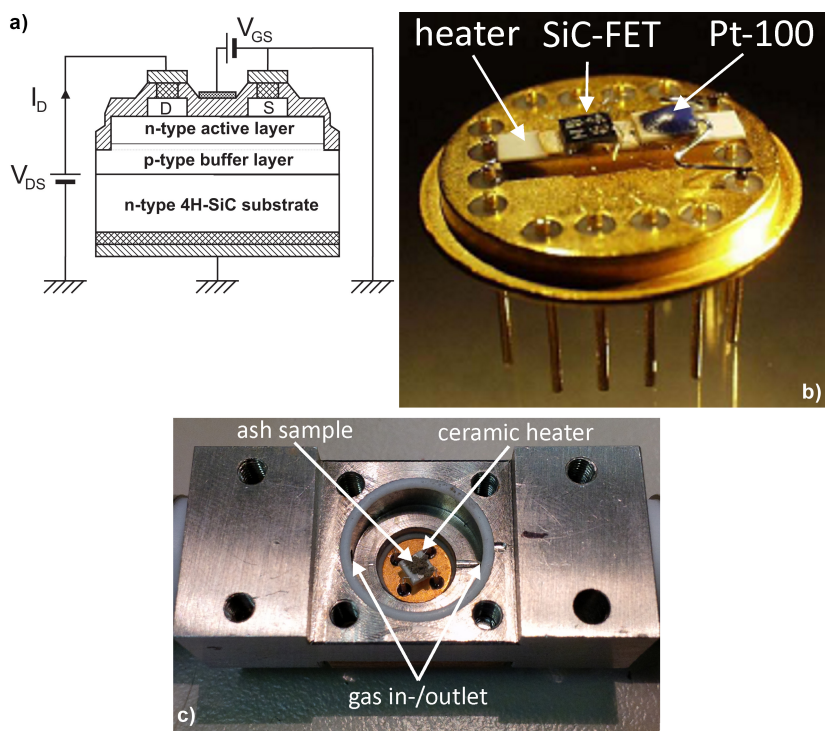

Figure 2. (a) Cross-sectional view of the SiC-FET used. (b) Picture of the SiC-FET sensor mounted on a TO-8 header. (c) Picture of the stainless steel heater chamber holding a ceramic header mounted on a TO-5 header with some ash on top.

placed next to the $\mathrm{SiC}$ chip in order to measure the actual temperature. The SiC-FET chip and the Pt-100 were glued on the surface of the heater using a high-temperature, nonconducting ceramic die. The electrical contacts of the heater substrate and of the Pt-100 were established by spot welding to two pairs of pins of the gold-plated 16-pin TO8 header (cf. Fig. 2b). Electrical contacts to the FET structures on the SiC chip were made via gold wire bonding.

The SiC-FET was operated in a constant drain-current mode while the drain-source voltage was recorded as the sensor signal. Typical values of the current were in the range of 30 to $60 \mu \mathrm{A}$. Gate and substrate contacts of the transistor were grounded. In general, the baseline of the transistor can be adjusted by applying a bias to either the substrate or the gate, whereas the gate bias additionally influences the sensing behavior (Bur et al., 2014).

Sensor control and data acquisition was performed using a combined system developed by $3 \mathrm{~S} \mathrm{GmbH}$, Saarbrücken, Germany. The system controls the sensor temperature with an analog control circuit with a resolution of $1{ }^{\circ} \mathrm{C}$. Data acquisition is performed using a 14 bit analog-to-digital converter (ADC) measuring the drain-source voltage with a theoretical resolution of approximately $0.4 \mathrm{mV}$. The drain current can be set with an accuracy of less than $1 \mu \mathrm{A}$. The acquisition rate for all measurements was $10 \mathrm{~Hz}$.

\subsection{Ceramic heater platforms}

Sensor substrates from Umwelt Sensor Technik GmbH, Geschwenda, Germany, without a sensing layer were used as ceramic heaters. The substrates consist of a platinum heater
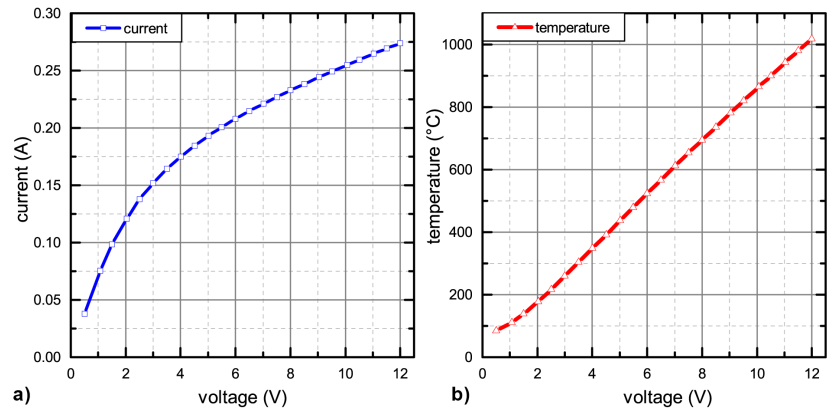

Figure 3. (a) Current-voltage characteristics of the ceramic heater used. (b) Derived temperature-voltage characteristics.

(Pt-10) on an alumina substrate with outer heater dimensions of $3 \mathrm{~mm} \times 3 \mathrm{~mm} \times 0.75 \mathrm{~mm}$ (Fig. 2c). In order to set the temperature, a voltage-resistance curve for the heater was recorded by applying a stepwise increasing voltage and simultaneously measuring the current. Based on this, a voltage-temperature characteristic (Fig. 3) was achieved. Temperature of the heater can be calculated accordingly:

$T=\frac{-A+\sqrt{A^{2}-4 \cdot B \cdot\left(-\frac{R}{R_{0}}+1\right)}}{2 \cdot B}$,

where $R=\frac{V}{I}$ is the resistance; $R_{0}$ is the resistance at $0^{\circ} \mathrm{C}$, here $10 \Omega$; and $A=3.9083 \times 10^{-3}{ }^{\circ} \mathrm{C}^{-1}$ and $B=-5.775 \times$ $10^{-7}{ }^{\circ} \mathrm{C}^{-2}$ are the parameters of the standard platinum curve.

\subsection{Test samples}

In order to study the suggested setup for measuring content of particles, ammonia $\left(\mathrm{NH}_{3}\right)$-contaminated fly ash from a coalfired power plant was used. This power plant uses a selective non-catalytic reduction (SNCR) system to reduce emissions of nitrogen oxides by injecting urea. The amount of ammonia in the fly ash was analytically determined by SGS Institute Fresenius, Germany. Test samples with varyingly high ammonia contaminations, i.e., 34, 64 and $84 \mathrm{mg} \mathrm{kg}^{-1}$ (milligram ammonia per kilogram of ash), were used for testing the proposed setup.

\subsection{Measurement setup}

As described in Sect. 2, the measurement setup consists of a heater chamber, two valves and a sensor chamber. The heater and sensor chamber are made of stainless steel, and three/two-way valves with PEEK housing and Kalrez (FFKM) sealing from Bürkert $\mathrm{GmbH}$, Ingelfingen, Germany (type 6608), were used. The connections between the different parts were made by $1 / 4 \mathrm{in}$. stainless steel Swagelok tubing. Dry synthetic air with a flow of $25 \mathrm{~mL} \mathrm{~min}^{-1}$ was used as carrier gas. For preliminary testing and validation, an environmental mass spectrometer (Hiden HPR20 running 


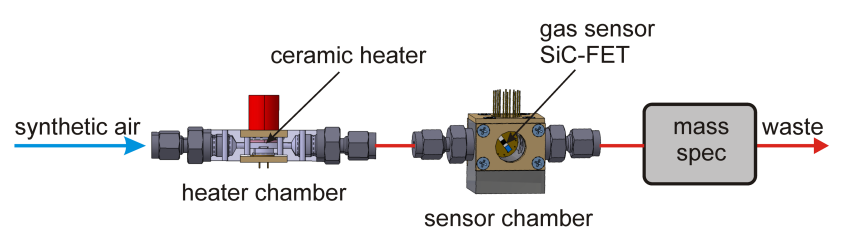

Figure 4. Schematic of the setup used with a mass spectrometer in the downstream.

MasSoft 7 Pro) was additionally placed downstream of the heater, i.e., without using the sensor chamber and later on also downstream of the sensor chamber as shown in Fig. 4. In this setup the valves and the bypass are not used since the mass spectrometer measurements are only applied for validation purposes. In this case, the ash was placed on top of the heater and the heating process started after the baseline of the SiC-FET had been stabilized, i.e., a few minutes after placement of the particles. Besides dry synthetic air, argon was also used as a carrier gas for mass spectrometer measurements. Using argon as carrier gas provides the possibility to follow the carbon monoxide (CO, $28 \mathrm{u})$ signal, which has the same mass as molecular nitrogen $\left(\mathrm{N}_{2}, 28 \mathrm{u}\right)$.

For each measurement a small pile of ash, approximately $1 \mathrm{mg}$, was placed on top of the heater (see Fig. 2c).

\section{Results and discussion}

In this chapter, results from silicon carbide field-effect transistors (SiC-FET) together with mass spectrometer data are presented. In Sect. 4.1 the desorbates from the ash heated up to several hundred degrees are analyzed by means of an environmental mass spectrometer. In the following section, reference measurements with a gas mixing system and the SiC-FETs are performed in order to allow comparison with the results presented in Sects. 4.3 and 4.4. The last section deals with the suggested bypass approach and can be seen as an extension of the paper.

\subsection{Characterization of fly ash}

As a first step, the heater chamber was directly connected to a mass spectrometer in order to analyze desorbing substances from the ash. Six different substances of interest, i.e., ammonia $\left(\mathrm{NH}_{3}, 17 \mathrm{u}\right)$, water vapor $\left(\mathrm{H}_{2} \mathrm{O}, 18 \mathrm{u}\right)$, nitrogen monoxide $(\mathrm{NO}, 30 \mathrm{u})$, carbon dioxide $\left(\mathrm{CO}_{2}, 44 \mathrm{u}\right)$, nitrogen dioxide $\left(\mathrm{NO}_{2}, 46 \mathrm{u}\right)$ and sulfur dioxide $\left(\mathrm{SO}_{2}, 64 \mathrm{u}\right)$, were chosen to be monitored during the measurements. Although it is known that the ash samples are ammonia-contaminated, $\mathrm{NO}_{\mathrm{x}}$ and $\mathrm{SO}_{\mathrm{x}}$ are probably also contained in the ash since it is a byproduct of combustion processes. Figure 5 shows the mass spectra when a small pile $(\sim 1 \mathrm{mg})$ of ammoniacontaminated ash (here: $84 \mathrm{mg} \mathrm{kg}^{-1}$ ) is heated up to 430 and $860^{\circ} \mathrm{C}$. At $430^{\circ} \mathrm{C}$ ammonia and water can be desorbed from the ash (cf. Fig. 5a), whereas there is no signal for the other substances. The change in mass spectra corresponding to the second heating pulse greatly decreased, which is plausible since most of the contaminations had already desorbed by the first pulse. In addition to ammonia, there is also water vapor adsorbed to the ash particles, which is probably from the lab atmosphere. However, the signal for water is overlapping and similar in shape to the ammonia signal. This can partly be due to measurement errors, since both molecules have almost the same molecular weight (ammonia $17 \mathrm{u}$ and water $18 \mathrm{u}$ ). However, water is most probably present and then also influences the sensor response.

When the ash sample was heated up to $860^{\circ} \mathrm{C}$ not only $\mathrm{NH}_{3}$ and $\mathrm{H}_{2} \mathrm{O}$ were desorbed but also large amounts of $\mathrm{NO}_{2}$, $\mathrm{SO}_{2}$ and $\mathrm{CO}_{2}$ (cf. Fig. 5b). Similar to ammonia and water, the peak heights decrease for the second and third heating pulse but the signal is still quite high. Whereas $\mathrm{CO}_{2}$ has almost no influence on the SiC-FET signal, $\mathrm{NO}_{2}$ and $\mathrm{SO}_{2}$, in contrast to ammonia, are known to be detected as oxidizing gases. Thus, when heating up the samples to high temperatures, both reducing and oxidizing gases will be desorbed. The effects from oxidizing and reducing gases on the sensor signal may partly cancel out when these gases are simultaneously desorbed from the particles since they give rise to opposing sensor responses. However, since the heater that was used has a time constant of a few seconds, there is a period of temperature increase at the beginning of each pulse. Therefore, ammonia and water are released first, followed by the other substances.

Since there is a large amount of $\mathrm{CO}_{2}$ outgassing, it is likely that $\mathrm{CO}$, which can be detected by the SiC-FETs, is also present. However, when using synthetic air as a carrier gas, one cannot follow carbon monoxide due to the fact that it has the same mass as molecular nitrogen $\left(\mathrm{N}_{2}, 28 \mathrm{u}\right)$. A small change due to degassing $\mathrm{CO}$ cannot be resolved by the mass spectrometer when using synthetic air. Hence, argon was used as a carrier gas instead. For heating pulses up to $430^{\circ} \mathrm{C}$, neither $\mathrm{CO}_{2}$ nor $\mathrm{CO}$ is released from the ash (Fig. 6a). However, at higher temperatures (e.g., $\left.860^{\circ} \mathrm{C}\right) \mathrm{CO}$ appears, which is a reducing gas as well (Fig. 6b). In summary, the heating temperature needs be chosen carefully in order to desorb the correct target gas. However, specific temperatures or a temperature ramp can be used for selective desorption and fingerprint detection of desorbants.

\subsection{Reference measurement of ammonia and humidity}

Before measuring desorbates from ash samples, reference measurements were performed with a platinum gate $\mathrm{SiC}$ FET. Figure 7a shows the sensor responses to 1, 2.5, 4, 5.5 and $7 \mathrm{ppm}$ ammonia in synthetic air under dry conditions. The sensor response of a Pt-gate SiC-FET at $220^{\circ} \mathrm{C}$ is $110 \mathrm{mV}$ for $1 \mathrm{ppm}$ ammonia. The response of an Ir-gate $\mathrm{SiC}-\mathrm{FET}$ at $280^{\circ} \mathrm{C}$ is much lower, i.e., $53 \mathrm{mV}$ for $1 \mathrm{ppm}$ ammonia; however, Ir is more selective over, for example, hydrocarbons as compared to the Pt-gate SiC-FET (Andersson 

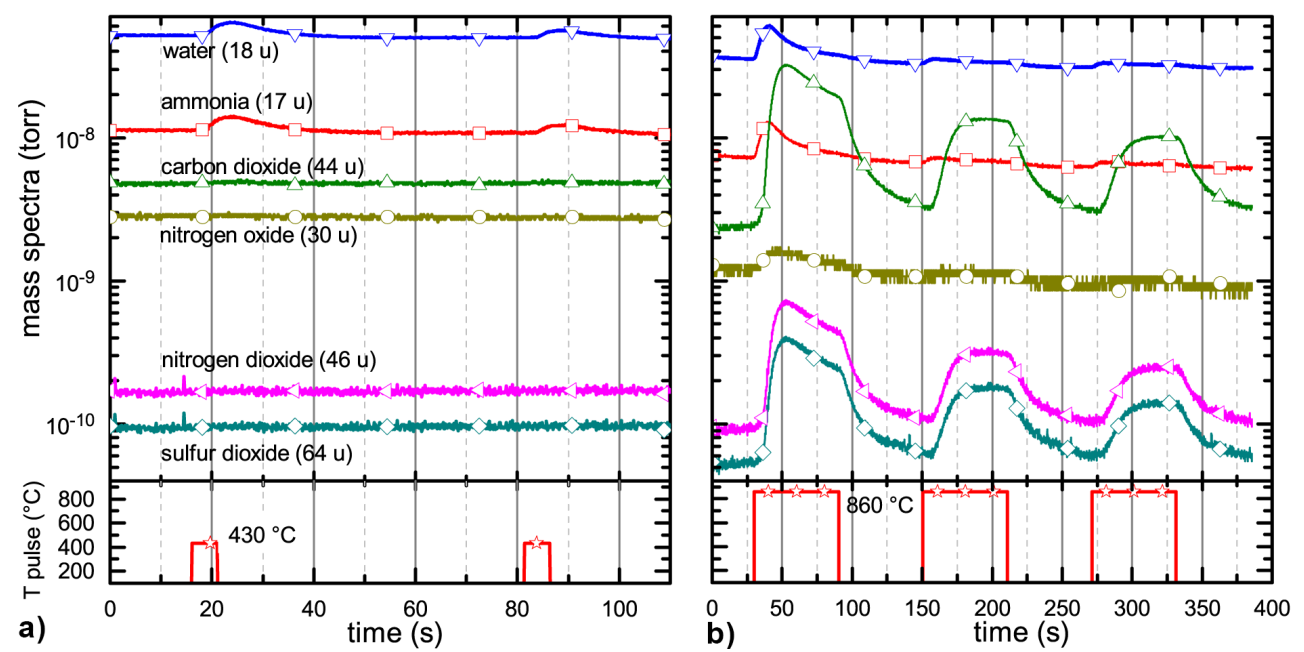

Figure 5. Mass spectra of ammonia-contaminated fly ash $\left(84 \mathrm{mg} \mathrm{kg}^{-1}\right)$ when heating up the ash to $430{ }^{\circ} \mathrm{C}$ (a) and $860^{\circ} \mathrm{C}(\mathbf{b})$. Carrier gas is dry synthetic air.
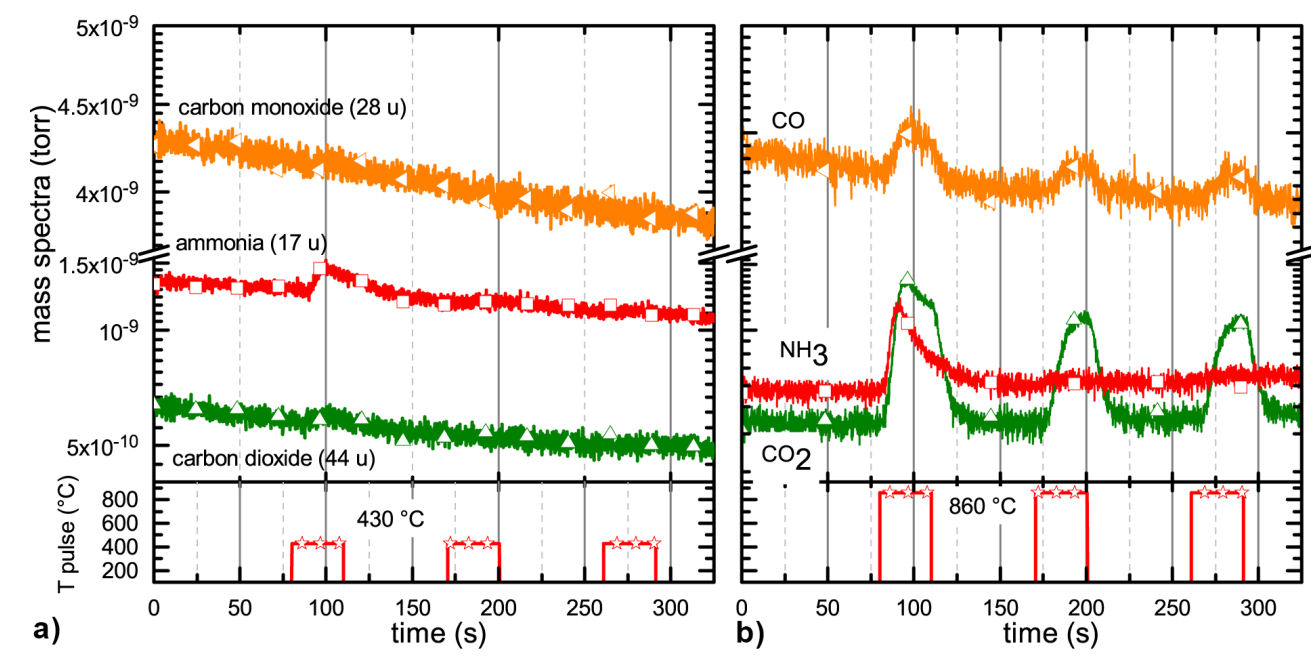

Figure 6. Mass spectra of ammonia-contaminated fly ash $\left(84 \mathrm{mg} \mathrm{kg}^{-1}\right)$ when heating up the ash to $430{ }^{\circ} \mathrm{C}(\mathbf{a})$ and $860^{\circ} \mathrm{C}(\mathbf{b})$. Carrier gas is argon.

et al., 2004). Iridium-gate SiC-FETs have been successfully used as ammonia sensors in diesel engine selective catalytic reduction (SCR) systems (Wingbrant et al., 2005).Therefore, iridium-gate $\mathrm{SiC}$-FETs should also be considered in this work.

As shown in Fig. 7b, humidity only has a minor impact on the sensor response (Wingbrant et al., 2005). There is a large difference in baseline between 0 and $10 \%$ relative humidity; however, with increasing humidity the impact becomes smaller. Since there is, besides ammonia, also water vapor desorbing from the ash particles, the corresponding sensor response is to some extent also due to a change in humidity.

Interested readers are referred to Andersson et al. (2004, 2013), in which the sensor response towards, for example, ammonia and carbon monoxide over a wide temperature range is studied. As mentioned earlier, the selectivity of the SiC-FET can be increased by dynamic operation (Bur et al., 2012a, b, 2014).

\subsection{SiC-FET response}

For preliminary measurements with a gas-sensitive SiC-FET, the setup shown in Fig. 4, where the sensor chamber is directly connected to the heater chamber, was used. In Fig. 8 the sensor response of a Pt-gate SiC-FET at $200{ }^{\circ} \mathrm{C}$ is given. In this example, the carrier gas stream has been humidified using a commercial PermaPure tube (Perma Pure, 2014) to the humidity level of the laboratory environment (approximately $30 \%$ ). This reduces the influence of degassing water vapor since SiC-FET sensors show almost no sensitivity to 

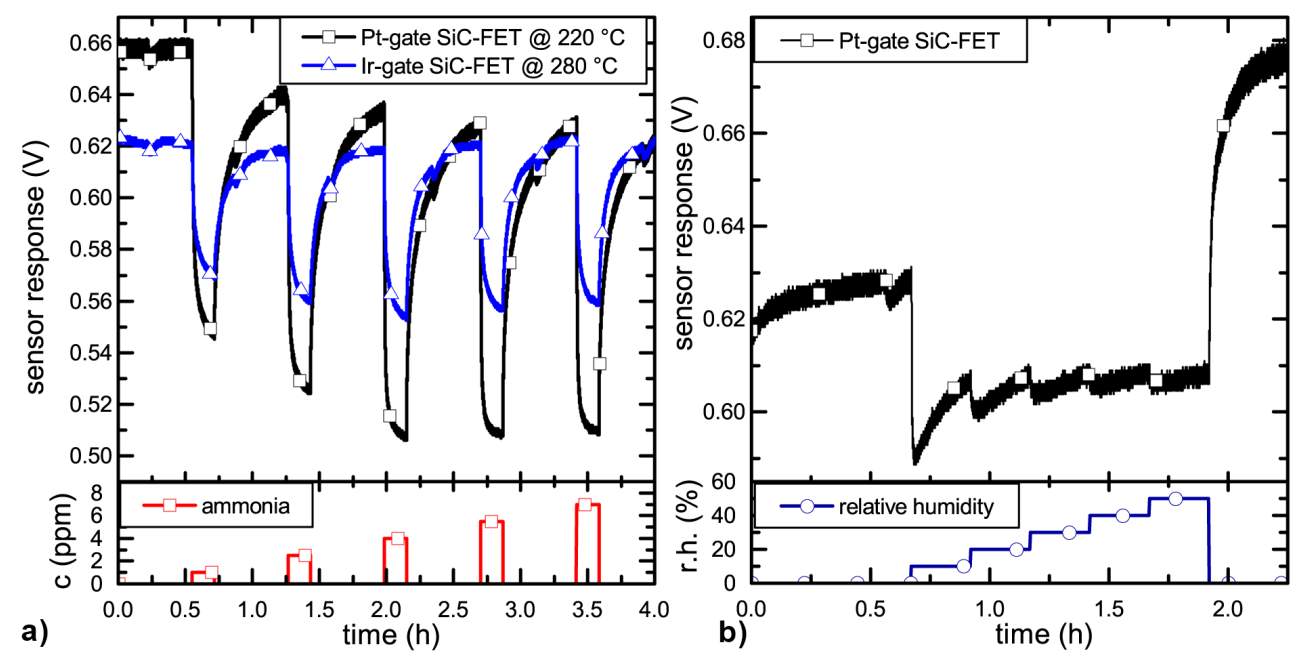

Figure 7. (a) Reference measurements of a Pt-gate $\mathrm{SiC}$-FETs at $220^{\circ} \mathrm{C}$ and Ir-gate $\mathrm{SiC}$-FET at $280^{\circ} \mathrm{C}$ to different concentrations $c(1,2.5$, 4, 5.5 and $7 \mathrm{ppm}$ ) of ammonia under dry conditions. (b) Influence of relative humidity $\mathrm{RH}$.

variations in humidity for RH higher than $10 \%$ (Wingbrant et al., 2005). Ammonia-contaminated fly ash $\left(84 \mathrm{mg} \mathrm{kg}^{-1}\right)$ was placed on top of the heater which was mounted in the heater chamber. First, two heating pulses up to $430^{\circ} \mathrm{C}$ with $30 \mathrm{~s}$ each and a break of $120 \mathrm{~s}$ in between were applied, followed by two pulses up to $860^{\circ} \mathrm{C}$. The first pulse desorbs most of the ammonia as proven by mass spectrometer measurements. The response of the SiC-FET decreases by approximately $80 \mathrm{mV}$ due to the release of ammonia and water. The two high-temperature pulses lead to desorption of nitrogen dioxide and sulfur dioxide, as well as additional ammonia, water and carbon monoxide (shown in Fig. 6b). Thus, the response of the SiC-FET decreases first (reducing gases) due to the long thermal time constant of the heater (approximately 3-4s), but shortly thereafter the response increases significantly, which is due to the reaction of oxidizing gases. The response is lowered for the second heating pulse, which suggests that substances are indeed desorbing from ash particles.

In order to see the influence of the heating pulses, the temperature of the heater was increased stepwise from 180 to $860^{\circ} \mathrm{C}$. As can be seen in Fig. 9, some ammonia can already be desorbed at low temperatures; however, the maximum sensor response is reached around $400^{\circ} \mathrm{C}$. Of course, with each pulse, ammonia is released and the amount of ammonia still adsorbed to the ash decreases. Nevertheless, in comparison with other results, higher temperatures (above $600^{\circ} \mathrm{C}$ ) cause the release of oxidizing (here unwanted) gases. This is also visible in the SiC-FET response in Fig. 9. The decreasing peaks in the response corresponding to 700,780 and $860^{\circ} \mathrm{C}$ pulses are due to reducing gases, probably carbon monoxide, as shown in Fig. 6b. However, the influence of the oxidizing gases is still visible as indicated in Fig. 9.

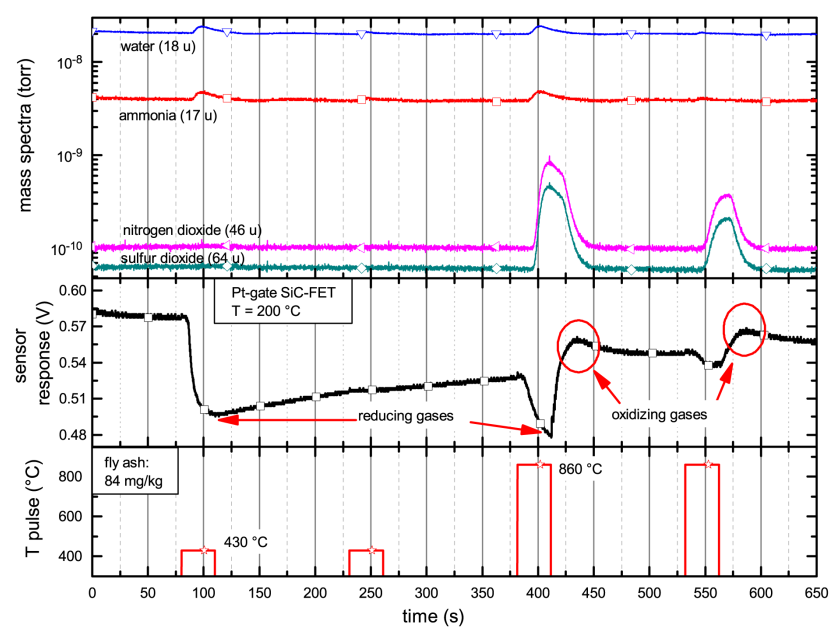

Figure 8. Top: mass spectra; middle: sensor response of a Pt-gate SiC-FET at $200^{\circ} \mathrm{C}$; bottom: heating pulses to 430 and $860^{\circ} \mathrm{C}$ of ammonia-contaminated fly ash $\left(84 \mathrm{mg} \mathrm{kg}^{-1}\right)$. With PermaPure tube for humidifying the carrier gas (synthetic air).

In further measurements, SiC-FETs with platinum as well as with iridium were used as the gate metallization. Results shown in Fig. 10 (without a PermaPure tube) indicate that iridium has a shorter recovery time after exposure to ammonia and is slightly more sensitive since the sensor also detects the release of ammonia from the second and third pulse. The operating temperature of the sensor was $280^{\circ} \mathrm{C}$ and therefore higher than for platinum, which is due to the fact that iridium is less catalytically active than platinum, making a higher temperature necessary (Andersson et al., 2004).

When applying $650^{\circ} \mathrm{C}$ pulses to the ash sample, the Irgate FET only shows a decreasing response which corresponds to reducing gases (cf. Fig. 11), i.e., ammonia and 


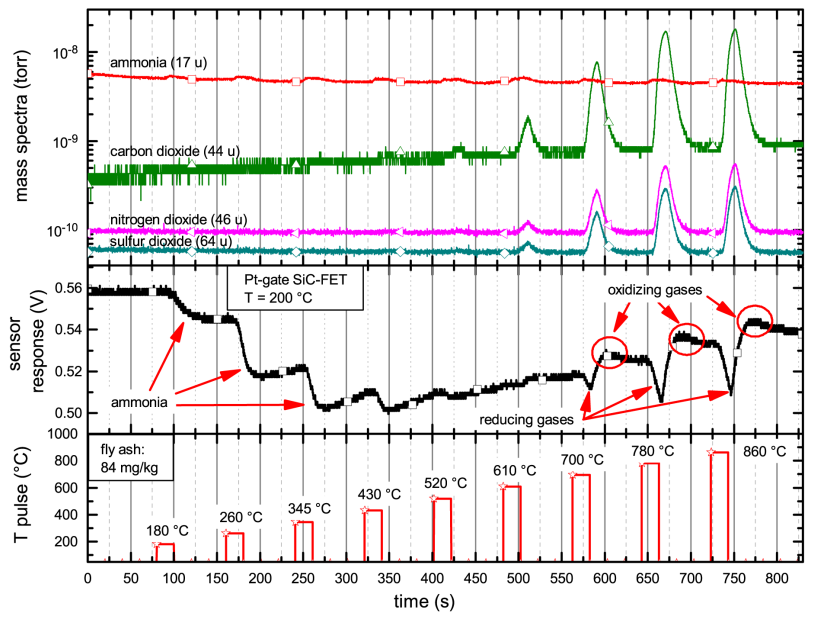

Figure 9. Top: mass spectra; middle: sensor response of a Pt-gate SiC-FET at $200^{\circ} \mathrm{C}$; bottom: heating pulses from 180 to $860^{\circ} \mathrm{C}$ of ammonia-contaminated fly ash $\left(84 \mathrm{mg} \mathrm{kg}^{-1}\right)$. With PermaPure tube for humidifying the carrier gas (synthetic air).

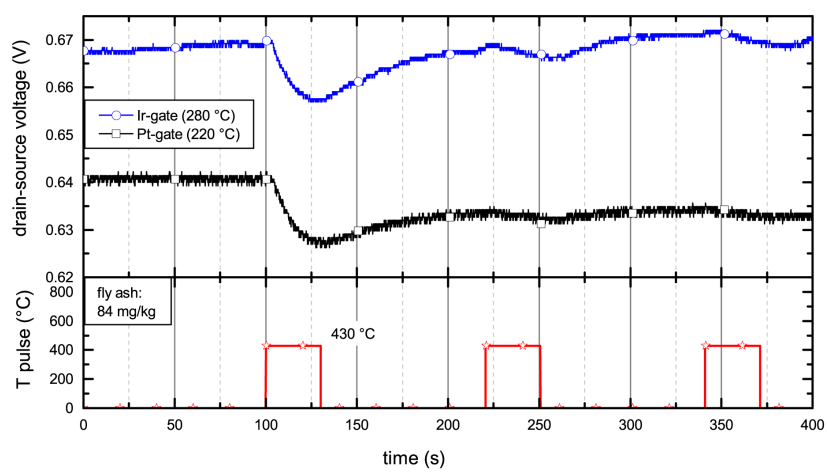

Figure 10. Top: sensor responses of Pt- and Ir-gate SiC-FETs at 220 and $280^{\circ} \mathrm{C}$ respectively. Bottom: heating pulses up to $430^{\circ} \mathrm{C}$.

carbon monoxide. For the Pt-gate SiC-FET there is almost no response for the second and third pulse. In general the response for the second and third pulse decreases greatly as compared to the first pulse, which is due to the fact the first pulse already releases most of the adsorbates. However, the FET sensors detect oxidizing gases, but only if the sample is heated up to more than $700^{\circ} \mathrm{C}$ (cf. Figs. 8 and 9).

The results in Figs. 10 and 11 suggest increasing the operating temperature of the sensor in order to reduce the recovery time, i.e., to clean the surface. However, at higher temperatures the sensitivity to ammonia is lower. Thus, temperature-cycled operation (TCO) could be used with a temperature cycle consisting of two phases: a lowtemperature phase, i.e., $220^{\circ} \mathrm{C}$ for platinum and $280^{\circ} \mathrm{C}$ for iridium-gate $\mathrm{SiC}-\mathrm{FETs}$, at which the sensing takes place, and a high-temperature phase just for cleaning the sensor surface. When using TCO, the temperature cycling of the FET needs

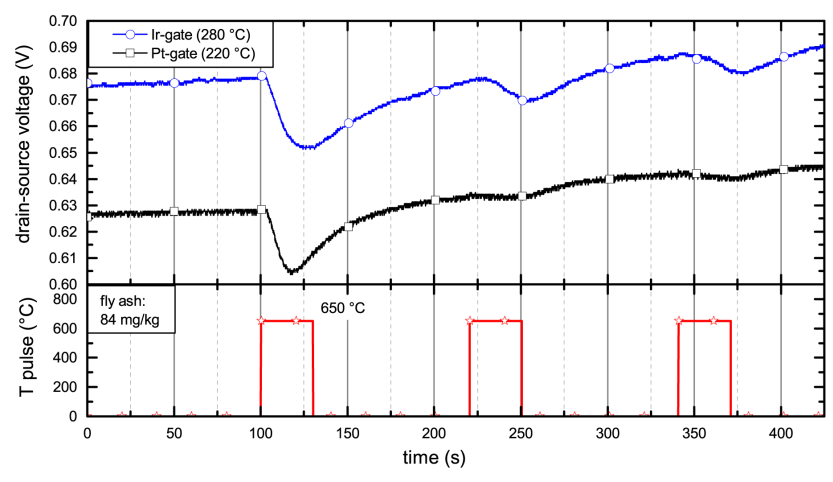

Figure 11. Top: sensor responses of Pt- and Ir-gate SiC-FETs at 220 and $280^{\circ} \mathrm{C}$, respectively. Bottom: heating pulses up to $650^{\circ} \mathrm{C}$.

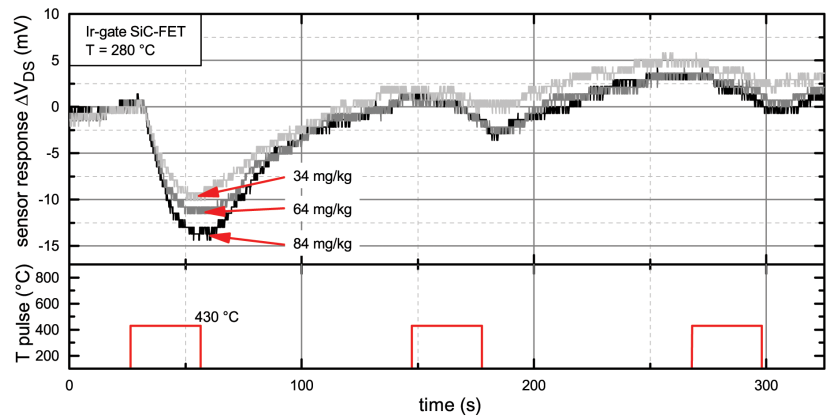

Figure 12. Top: difference signal of an Ir-gate FET at $280^{\circ} \mathrm{C}$ to different concentration of ammonia $\left(34,64,84 \mathrm{mg} \mathrm{kg}^{-1}\right)$. Bottom: heating pulses up to $430^{\circ} \mathrm{C}$.

to be synchronized with the heating and as appropriate with switching of the valves. Future work will address TCO.

\subsection{Different concentrations}

Figure 12 shows the sensor response to differently contaminated ash particles when they are heated up to $430^{\circ} \mathrm{C}$. As can be seen, the absolute value of the sensor response changes with the ammonia concentration. However, not only the absolute response but also the shape of the response depends on the ammonia concentration. Shape-describing features in particular can be used in pattern recognition for discrimination purposes (Marco and Gutiérrez-Gálvez, 2012; Bur et al., 2012a, b, 2014).

For lab measurements performed here, the amount which is placed manually on top of the heater is quite well defined. However, in general the amount of ash put on the heater is crucial and strongly affects the height of the sensor response. This issue will have to be solved for a miniaturized portable particle analyzer. 


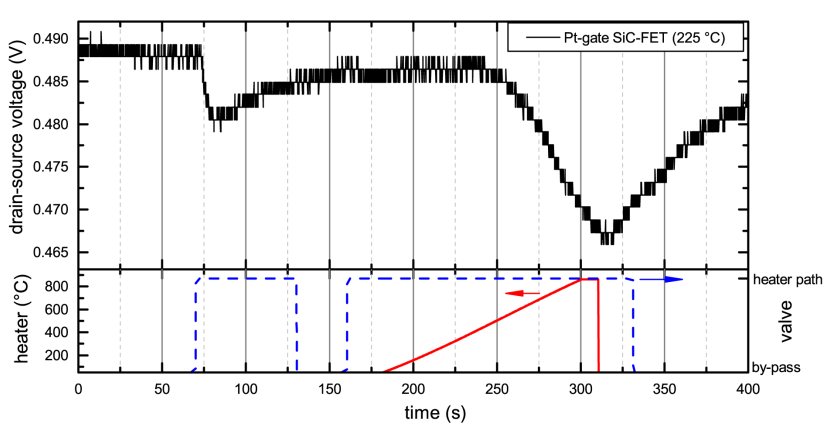

Figure 13. Sensor response of a Pt-gate SiC-FET at $225^{\circ} \mathrm{C}$. Bottom: heating ramp and valve position.

\subsection{Measurements with valves}

As mentioned in the beginning, our first idea was to use a bypass approach (shown in Fig. 1) in order to always have a well-defined and controlled flow over the gas sensor for baseline stability purposes. This section will briefly show the possibilities the proposed setup shown in Fig. 1, and thus the section should be seen as an outlook. While the ash sample is placed on the heater, the carrier gas is flowing through the bypass to the gas sensor. During that time the baseline of the sensor stabilizes. Before the heating starts, the valves need to switch once in order to exchange the air in the heater chamber since there is a huge difference in baseline if lab air or synthetic air is used. Figure 13 shows the SiC-FET sensor response for a measurement where the bypass is used. As can be seen, the sensor signal decreases during the first switching of the valves (not heating at this point). This is mainly the influence of the trapped lab air in the heater chamber. The actual measurement with fly ash can first begin when the baseline has stabilized again. After that, there are several options how to perform the test, which will be the aim of future work: heating and switching of the valves can be done asynchronously, which means that ammonia can first be accumulated and then be transferred to the gas sensor. Another option is to open the valves right before starting the heating process (shown in Fig. 13). Not only the measurement procedure itself but also the heating process can be changed. In Fig. 13 a heating ramp was used instead of the pulses used before. However, from our experience, a quick raise of temperature is more adequate to desorb substances from the particles. With a temperature ramp the ammonia is desorbed slowly, whereas a quick heating-up leads to a rather sharp release. As mentioned earlier, the different ammonia concentrations can be distinguished not only by the absolute value of the SiC-FET response but to some extent also by the slope of the response. For the later one, a temperature ramp would not be possible, but a heating cycle with a few defined temperatures may still be useful, especially together with smart data evaluation, in order to detect different gas molecules.

\section{Conclusions and outlook}

In this work a measurement methodology for investigating content of particles has been presented. It was shown that attached substances were desorbed by heating up particles (here: fly ash) with a small ceramic heater to temperatures up to $860^{\circ} \mathrm{C}$. Mass spectrometer measurements proved that ammonia and water are released from these particular particles mainly at lower temperatures, whereas temperatures above $600^{\circ} \mathrm{C}$ lead to the formation and/or release of carbon monoxide, nitrogen- and sulfur dioxides, as well as carbon dioxide. The released gases were detected by silicon carbide field-effect transistors (SiC-FETs) with platinum or iridium as gate materials.

Future work will address the optimization of the gas sensor, e.g., operating temperature and operating mode. For discrimination and quantification, temperature- and/or bias modulation of the gas sensor is an appropriate method. However, since the release of ammonia is quite short, the corresponding temperature or bias cycle of the gas sensor needs to be short as well. Another benefit of the dynamic operation is that a high-temperature phase in the cycle can be used to clean the surface of the sensor and thus shorten the recovery time. Alternatively, the gas sensor can be operated at constant temperature and discrimination/quantification of outgassing substances can tentatively be achieved by using features describing the shape of the response similar to temperature-cycled operation (Bur et al., 2012a, b). The presented method is currently under development for integration into a low-temperature cofired ceramics (LTCC)-based package (Sobocinski et al., 2014) by our colleagues at the University of Oulu, Finland.

Acknowledgements. The authors would like to thank SenSiC $\mathrm{AB}$, Kista, Sweden, for providing the sensors and $3 \mathrm{~S}$ - Sensors, Signal Processing, Systems GmbH, Saarbrücken, Germany, for providing the hardware for sensor operation and read-out.

C. Bur acknowledges support through the "European Network on New Sensing Technologies for Air-Pollution Control and Environmental Sustainability, " (EuNetAir) for a "short-term scientific mission" (STSM) at the University of Oulu, Finland.

A. Lloyd Spetz and M. Andersson acknowledge a grant from the Funding Agency for Innovations - TEKES, Finland, (project CHEMPACK, no. 1427/31/2010.)

Edited by: M. Meyyappan

Reviewed by: two anonymous referees

\section{References}

Amanatidis, S., Ntziachristos, L., and Samaras, Z.: Applicability of the Pegasor Particle Sensor to Measure Particle Number, Mass and PM Emissions, SAE Technical Paper, 2013-24-0167, doi:10.4271/2013-24-0167, 2013.

Andersson, M., Ljung, P., Mattsson, M., Löfdahl, M., and Lloyd Spetz, A.: Investigations on the possibilities of a MISiCFET sen- 
sor system for OBD and combustion control utilizing different catalytic gate materials, Top. Catal., 30/31, 365-368, 2004.

Andersson, M., Everbrand, L., Lloyd Spetz, A., Nyström, T., Nilsson, M., Gauffin, C., and Svensson, H.: A MISiCFET based gas sensor system for combustion control in small-scale wood fired boilers, Proc. IEEE Sensors, Atlanta, USA 28-31 October, 962-965, 2007.

Andersson, A., Pearce, R., and Lloyd Spetz, A.: New generation $\mathrm{SiC}$ based field effect transistor gas sensors, Sensor. Actuat. B, 179, 95-106, 2013.

Bartscherer, P. and Moos, R.: Improvement of the sensitivity of a conductometric soot sensor by adding a conductive cover layer, J. Sens. Sens. Syst., 2, 95-102, doi:10.5194/jsss-2-95-2013, 2013.

Bjorklund, R., Grant, A., Jozsa, P., Johansson, M., Fägerman, P. E., Paaso, J., Andersson, M., Hammarlund, L., Larsson, A., Popovici, E., Lutic, D., Pagels, J., Sanati, M., and Lloyd Spetz, A.: Soot sensor based on thermophoresis for high sensitive soot detection in diesel exhausts, in: Proc. IMCS13, Perth, Australia, 2010.

Bur, C., Reimann, P., Andersson, M., Schütze, A., and Lloyd Spetz, A.: Increasing the selectivity of Pt-Gate SiC field effect gas sensors by dynamic temperature modulation, IEEE Sens. J., 12, 1906-1913, 2012a.

Bur, C., Reimann, P., Andersson, M., Lloyd Spetz, A., and Schütze, A.: New method for selectivity enhancement of SiC field effect gas sensors for quantification of $\mathrm{NO}_{\mathrm{x}}$, Microsyst. Technol., 18, 1015-1025, 2012b.

Bur, C., Bastuck, M., Lloyd Spetz, A., Andersson, M., and Schütze, A.: Selectivity enhancement of SiC-FET gas sensors by combining temperature and gate bias cycled operation using multivariate statistics, Sensor. Actuat. B-Chem., 193, 931-940, 2014.

Buzea, C., Pacheco, I. I., and Robbie, K.: Nanomaterials and nanoparticles: sources and toxicity, Biointerphases, 2, MR17-MR71, 2007.

Darmastuti, Z., Bur, C., Möller, P., Rahlin, R., Lindqvist, N., Andersson, M., Schütze, A., and Lloyd Spetz, A.: SiC-FET based $\mathrm{SO}_{2}$ sensor for power plant emission applications, Sens. Actuat. B-Chem., 194, 511-520, 2014.

Geiling, T., Dressler, L., Welker, T., and Hoffmann, M.: Fine dust measurement with electrical fields - concept of a hybrid particle detector, 9th IMAPS/ACerS Intern. Conf. and Exhibition on Ceramic Interconnect and Ceramic Microsystems Technologies, CICMT 2013, Orlando, Florida, USA, 23-25 April, 2013.

Lanki, T., Tikkanen, J., Kauko, J., Taimisto, P., and Lehtimäki, M.: An electrical sensor for long-term monitoring of ultrafine particles in workplaces, J. Phys. Conf. Ser., 304, 012013, doi:10.1088/1742-6596/304/1/012013, 2011.

Larsson, O., Göras, A., Nytomt, J., Carlsson, C., Lloyd Spetz, A., Artursson, T., Holmberg, M., Lundström, I., Ekedahl, L.-G., and Tobias, P.: Estimation of air fuel ratio of individual cylinders in SI engines by means of MISiC sensor signals in a linear regression model, AE Technical Paper 2002-01-0847, doi:10.4271/200201-0847, 2002.
Lloyd Spetz, A., Baranzahi, A., Tobias, P., and Lundström, I.: High temperature sensors based on metal insulator silicon carbide devices, Phys. Status Solidi A, 162, 493-511, 1997.

Lloyd Spetz, A. and Svage, S.: Silicon Carbide - Recent Major Advances, edited by: Choyke, W. J., Matsunami, H., and Pensl, G., Springer, Berlin, Heidelberg, ISBN 978-3-642-18870-1, 2003.

Lloyd Spetz, A., Huotari, J., Bur, C., Bjorklund, R., Lappalainen, J., Jantunen, J., Schütze, A., and Andersson, M.: Chemical sensor systems for emission control from combustions, Sensor Actuat. B-Chem., 187, 184-190, 2013.

Lundström, I., Sundgren, H., Winquist, F., Eriksson, M., KrantzRülcker, C., and Lloyd Spetz, A.: "Twenty-five years of field effect gas sensor research in Linköping”, Sens. Actuat. B-Chem., 121, 247-262, 2007.

Marco, S. and Gutiérrez-Gálvez, A.: Signal and data processing for machine olfaction and chemical sensing: a review, IEEE Sens. J., 12, 3189-3214, 2012.

Messerer, A., Niessner, R., and Pöschl, U.: Thermophoretic deposition of soot aerosol particles under experimental conditions relevant for modern diesel engine exhaust gas systems, J. Aerosol Sci., 34, 1009-1021, 2003.

NIOSH - National Institute for Occupational Safety and Health (NIOSH): Current Intelligence Bulletin 65: Occupational Exposure to Carbon Nanotubes and Nanofibers, DHHS (NIOSH) Publication No. 2013-145, 2013.

Ntziachristos, L., Fragkiadoulakis, P., Samaras, Z., Janka, K., and Tikkanen, J.: Exhaust Particle Sensor for OBD Application, SAE Technical Paper 2011-01-0626, doi:10.4271/2011-01-0626, 2011.

Osite, A., Katkevich, J., Viksna, A., and Vaivars, G.: Electrochemical impedance spectra of particulate matter and smoke, IOP Conference Series: Materials Science and Engineering, 23, 2011.

Perma Pure: ME Series moisture exchanger, available at: http: //www.permapure.com/, last access: September 2014.

Sobocinski, M., Lloyd Spetz, A., Andersson, M., Juuti, J., and Jantunen, H.: Novel method for integration of SiC in LTCC, Abstract book, 14th Electroceramics conference, Bucharest, Romania, June 16-20, 2014.

Thomas, S., Racz, Z., Cole, M., and Gardner J. W.: Dual highfrequency surface acoustic wave resonator for ultrafine particle sensing, Proc. IEEE Sensors Baltimore, MA, USA, 4-6 November, 1-4, 2013.

Wingbrant, H., Svenningstorp, H., Salomonsson, P., Kubinski, D., Visser, J. H., Löfdahl, M., and Lloyd Spetz, A.: Using a MISiCFET sensor for detecting NH3 in SCR systems, IEEE Sens. J., 5, 1099-1105, 2005.

$\mathrm{Xu}, \mathrm{R}$. Light scattering: a review of particle characterization applications, Particuology, in press, doi:10.1016/j.partic.2014.05.002, 2014. 